\title{
ANALISIS KUALITAS PELAYANAN DAN PENGENDALIAN KUALITAS JASA BERDASARKAN PERSEPSI PENGUNJUNG (STUDI KASUS: KUALITAS PELAYANAN DI KANTOR POS PADANG)
}

\author{
MAISAN NUSA PUTRI, YUDIANTRI ASDI, DAN DODI DEVIANTO \\ Jurusan Matematika, \\ Fakultas Matematika dan Ilmu Pengetahuan Alam, Universitas Andalas, \\ Kampus UNAND Limau Manis Padang, Indonesia, \\ email : mesannusai@gmail.com
}

\begin{abstract}
Abstrak. Kualitas pelayanan yang baik merupakan salah satu titik ukur dari perkembangan suatu perusahaan atau instansi. Hal tersebut dapat dinilai dari kepuasan pelanggan terhadap pelayanan yang diberikan perusahaan tersebut. Pada penelitian ini, akan diamati kualitas pelayanan jasa pada Kantor Pos Padang yang bertujuan untuk mengetahui persepsi pengunjung terhadap variabel-variabel dalam dimensi kualitas jasa, dengan menggunakan metode Importance Performance Analysis (IPA), metode Customer Satisfaction Index (CSI), dan Bagan kendali $T^{2}$ Hotelling. Hasil penilaian dari Importance Performance Analysis (IPA) terdiri dari dua komponen, pertama dapat dilihat dari analisis kuadran terdapat tujuh variabel yang diprioritaskan untuk ditingkatkan yaitu kebersihan ruangan, fasilitas pendukung seperti tempat fotocopy, toilet, dan mushalla, kedisiplinan petugas, ketepatan waktu pengiriman, kelancaran pelayanan, keramahan petugas, dan kesabaran petugas. Sementara itu, untuk komponen kedua yaitu analisis gap diporelah kinerja Kantor Pos berada di bawah kepentingan Kantor Pos. Dari hasil perhitungan Customer Satisfactin Index (CSI) diperoleh 79,55\%, hal ini berarti secara umum pengunjung Kantor Pos merasa puas terhadap pelayanan yang diberikan. Berdasarkan bagan kendali $T^{2}$ Hotelling pada data kinerja dan kepentingan Kantor Pos menunjukkan output bagan kendali belum terkendali karena terdapat beberapa pengamatan yang berada di luar batas kendali, sehingga dapat dikatakan kualitas pelayanan yang diberikan Kantor Pos belum terkendali.
\end{abstract}

Kata Kunci: Bagan kendali $T^{2}$ Hotelling, Customer Satisfaction Index (CSI), Kepuasan pelanggan, Importance Performance Analysis (IPA)

\section{Pendahuluan}

Perkembangan dunia bisnis dan perindustrian yang semakin pesat mendorong perusahaan untuk menjaga kualitas dari produk atau jasa yang dihasilkan untuk mempertahankan keberadaannya. Hal ini dikarenakan, kualitas merupakan salah satu dasar keputusan konsumen dalam memilih produk atau jasa yang akan digunakan. Banyak produk atau jasa yang bermunculan dengan berbagai macam jenis, mutu, dan bentuk, dimana keseluruhan tersebut ditujukan untuk menarik minat pelanggan. Oleh karena itu, setiap perusahaan dituntut agar mampu menciptakan produk atau jasa dengan melakukan proses yang terbaik agar kepuasan pelanggan terpenuhi. Dalam hal ini, dapat dikatakan bahwa kualitas memiliki hubungan yang erat dengan kepuasan pelanggan. 
Penelitian ini mengkaji lebih dalam bagaimana pemetaan hubungan tingkat kinerja dan kepentingan dari masing-masing variabel yang diberikan oleh pihak pengelola jasa Kantor Pos, melihat kesenjangan (gap) antara tingkat kinerja dengan kepentingan dari variabel-variabel tersebut, melihat kepuasan pengunjung secara keseluruhan, beserta memonitor variabel-variabel apa saja yang harus dipertahankan dan diperbaiki.

\section{Kualitas Pelayanan Jasa}

Kualitas jasa berpusat pada upaya pemenuhan dan keinginan pelanggan serta ketepatan penyampainnya untuk mengimbangi harapan pelanggan. Ada lima dimensi kualitas jasa, yaitu [3]:

(1) Tangibles (bukti langsung), meliputi fasilitas fisik, perlengkapan, penampilan pegawai, dan sarana komunikasi.

(2) Reliability (keandalan), yakni kemampuan memberikan pelayanan yang dijanjikan dengan secara tepat, akurat, dan memuaskan.

(3) Responsiveness (daya tanggap), yakni keinginan dan kesediaan para karyawan untuk membantu para pelanggan dan memberikan layanan dengan cepat tanggap.

(4) Assurance (jaminan), mencakup pengetahuan, kemampuan, kesopanan, sifat dapat dipercaya yang dimiliki para karyawan, bebas dari bahaya dan risiko, dan keragu-raguan.

(5) Emphaty (empati), meliputi kemudahan dalam menjalin hubungan, komunikasi yang efektif, perhatian personal, dan pemahaman atas kebutuhan individual para pelanggan.

Pengujian statistik yang digunakan pada penelitian ini adalah validitas dan reliabilitas. Uji validitas bertujuan untuk melihat kevaliditan suatu data yang dilakukan dengan menghitung korelasi product moment yang dilanjutkan dengan melakukan uji $r$. Uji reliabilitas bertujuan untuk melihat kekonsistenan suatu data yang dilakukan dengan menghitung koefisien reliabilitas (Alpha Cronbach) menggunakan persamaan

$$
C_{x \alpha}=\left(\frac{k}{k-1}\right)\left(1-\frac{\sum_{j=1}^{k} \sigma_{x j}^{2}}{\sigma_{x}^{2}}\right)
$$

Keterangan.

$$
\begin{aligned}
& \sigma_{x}^{2}=\text { variansi skor total } \\
& \sigma_{x j}^{2}=\text { variansi skor setiap pertanyaan }
\end{aligned}
$$

\subsection{Customer Satisfaction Index (CSI)}

Customer Satisfaction Index (CSI) digunakan utnuk mengetahui tingkat kepuasan pengunjung secara menyeluruh dengan melihat tingkat kepentingan dari variabelvariabel produk/jasa. Adapun langkah-langkah untuk menentukan CSI, yaitu: 
(1) Mean Satisfaction Score (MSS)

$$
M S S_{j}=\frac{\sum_{i=1}^{n} x_{i j}}{n}
$$

(2) Mean Importance Score (MIS)

$$
M I S_{j}=\frac{\sum_{i=1}^{n} y_{i j}}{n}
$$

(3) Weighting Factors (WF)

$$
W F_{j}=\frac{M I S_{j}}{\sum_{j=1}^{p} M I S_{j}} \times 100 \%
$$

(4) Weighted Score (WS)

$$
W S_{j}=W F_{j} \times M S S_{j}
$$

(5) Customer Satisfaction Index (CSI)

$$
C S I=\frac{\sum_{j=1}^{p} W S_{j}}{H S} \times 100 \%
$$

dengan HS: Highest Scale) $=$ skala maksimum yang digunakan

\subsection{Importance Performance Analysis (IPA)}

Importance Performance Analysis (IPA) terdiri atas dua komponen yaitu analisis kuadran dan analisis kesenjangan ( gap). Dengan analisis kuadran dapat menilai respon pengunjung terhadap variabel yang diplotkan berdasarkan rata-rata kinerja $\left(\bar{x}_{j}\right)$ pada sumbu $x$ dan rata-rata kepentingan $\left(\bar{y}_{j}\right)$ pada sumbu $y$ dalam diagram kartesius yang dibagi kedalam empat kuadran. Selanjutnya, menentukan nilai $\overline{\bar{x}}$ dan $\overline{\bar{y}}$ sebagai pembatas untuk masing-masing kuadran. Adapun setiap hasil menempati salah satu kuadran dalam diagram kartesius, yaitu

(1) Kuadran I (Prioritas Utama)

Memuat faktor-faktor yang dianggap penting oleh pelanggan, tetapi pada kenyataannya belum sesuai dengan harapan pelanggan (kinerjanya masih rendah).

(2) Kuadran II (Pertahankan Kinerja)

Memuat faktor-faktor yang dianggap penting oleh pelanggan dan tingkat kepuasannya relatif lebih tinggi (kinerjanya sudah tinggi)

(3) Kuadran III (Prioritas Rendah)

Memuat faktor-faktor yang dianggap kurang penting oleh pelanggan, tetapi pada kenyatannya kinerjanya masih rendah.

(4) Kuadran IV (Berlebihan)

Memuat faktror-faktor yang dianggap kurang penting dan dirasakan terlalu berlebihanoleh pelanggan (kinerjanya relatif tinggi).

Analisis kesenjangan ( $g a p$ ) digunakan untuk melihat kesenjangan antara kinerja dengan harapan pengunjung terhadap variabel tersebut. Besar kecilnya skor kesenjangan dilihat dari harga mutlak selisih antara kinerja kantor pos dengan kepentingan pengunjung. Semakin besar skor kesenjangan (gap) maka variabel atau dimensi tersebut semakin diprioritaskan untuk diperbaiki. 


\subsection{Uji Normal Multivariat}

Uji normal multivariat dapat dilakukan dengan cara membuat Chi-Square plot, yaitu [1]:

(1) Menghitung $d_{j}^{2}$ menggunakan persamaan

$$
d_{j}^{2}=\left(x_{j}-\bar{x}\right)^{\prime} S^{-1}\left(x_{j}-\bar{x}\right)
$$

(2) Mengurutkan nilai $d_{j}^{2}$ dari nilai terkecil sampai nilai yang terbesar yaitu $d_{(1)}^{2} \leq d_{(2)}^{2} \leq \ldots \leq d_{(n)}^{2}$

(3) Menentukan nilai $q_{(j)}=\chi_{p}^{2}\left(\frac{j-0,5}{n}\right)$ yang diperoleh dari tabel $\chi^{2}$,

(4) Membuat scatter-plot dengan memplotkan titik-titik antara $d_{j}^{2}$ dan $q_{(j)}$

\subsection{Bagan Kendali $T^{2}$ Hotelling}

Bagan Kendali $T^{2}$ Hotelling digunakan untuk pengendalian kualitas bersama-sama dua atau lebih karakteristik yang berhubungan. Untuk membuat bagan kendali $T^{2}$ Hotelling terlebih dahulu dicari vektor-vektor rata-rata sampel $(\overline{\mathbf{x}})$, matriks varian kovarian (S), kemudian dihitung nilai invers dari matriks $\mathbf{S}$. Nilai statistik $T^{2}$ untuk pengamatan ke- $j$ adalah:

$$
T_{j}^{2}=\left(\mathbf{x}_{\mathbf{j}}-\overline{\mathbf{x}}\right)^{\prime} \mathbf{S}^{-\mathbf{1}}\left(\mathbf{x}_{\mathbf{j}}-\overline{\mathbf{x}}\right)
$$

Kemudian dibuat plot bagan kendali antara nilai $T_{j}^{2}$ untuk setiap pengamatan, dimana batas kendalinya adalah [2]

$$
\begin{aligned}
\mathrm{BKA} & =\frac{(m-1)^{2}}{m} \beta_{\alpha, \frac{p}{2}, \frac{(m-p-1)}{2}} \\
\mathrm{BKB} & =0
\end{aligned}
$$

\section{Pembahasan}

Teknik pengambilan sampel dilakukan dengan cara Non-probability Sampling berupa Quota Sampling, yaitu metode pengambilan sampel dengan menentukan quota terlebih dahulu, sebelum quota terpenuhi maka penelitian belum selesai [5]. Sampel yang menjadi responden untuk penelitian ini sebanyak 268 orang. Pengumpulan data dilakukan secara bertahap yang dilakukan dengan cara menyebarkan kuesioner selama \pm empat minggu dalam hari kerja (Senin-Minggu).

\subsection{Customer Satisfaction Index (CSI)}

Berdasarkan hasil perhitungan MSS, MIS, WF, dan WS, dapat dihitung nilai Customer Satisfaction Index dengan $k=25$.

$$
C S I=\frac{\sum_{j=1}^{p} W S_{j}}{H S} \times 100 \%=79,55 \%
$$

Nilai CSI yang diperoleh menunjukkan pengunjung telah merasa puas terhadap pelayanan yang diberikan kantor pos. 


\subsection{Importance Performance Analysis (IPA)}

Dalam menentukan analisis kuadran pada metode IPA, terlebih dahulu ditentukan nilai $\overline{\bar{x}}$ dan $\overline{\bar{y}}$ sebagai pembatas untuk masing-masing kuadran.

$$
\overline{\bar{x}}=\frac{\sum_{j=1}^{25} \bar{x}_{j}}{25}=3,977, \quad \text { dan } \overline{\bar{y}}=\frac{\sum_{j=1}^{25} \bar{y}_{j}}{25}=4,493 .
$$

Nilai $\overline{\bar{x}}$ akan memotong secara tegak lurus pada sumbu horizontal di titik $(3,9947 ; 0)$ dan nilai $\overline{\bar{y}}$ memotong secara tegak lurus pada sumbu vertikal. Di titik $(0 ; 4,493)$. Gambar 1 menampilkan Analisis Kuadran kualitas pelayanan di kantor pos.

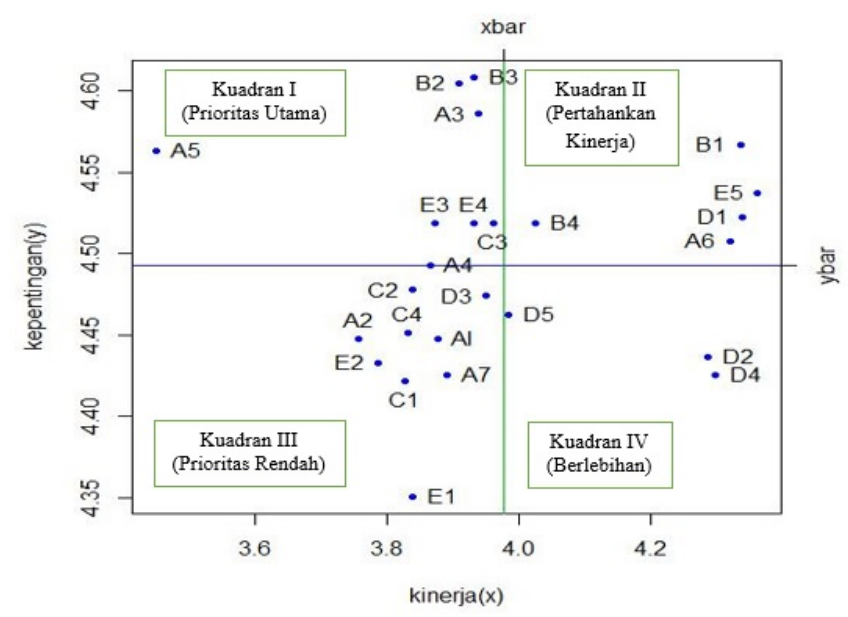

Gambar 1. Analisis Kuadran Kualitas Pelayanan di Kantor Pos

Metode Importance Performance Analysis (IPA) mengklasifikasikan tujuh variabel pada kuadran I yang memuat tingkat kepentingan tinggi, tetapi kinerjanya masih rendah yaitu kantor pos mempunyai ruangan yang bersih dan rapi (A3), kantor pos memberikan fasilitas pendukung seperti tempat fotocopy, toilet, mushalla, dll (A5), petugas tepat waktu dan disiplin dalam bekerja (B2), petugas melakukan pengiriman paket cepat dan tepat waktu (B3), petugas memberikan kelancaran kepada pengunjung dalam prosedur Pelayanan (C3), petugas ramah kepada pengunjung (E3), petugas sabar dalam menghadapi pengunjung (E4).

Pada kuadran II terdapat lima variabel yang memuat tingkat kepentingan tinggi dan kinerjanya juga tinggi yaitu kantor pos menyediakan papan informasi kepada pengunjung terkait dengan pembayaran, pengiriman surat/paket, dan lainnya (A6), petugas jujur dan dipercaya dalam pelayanan (B1), petugas membantu pengunjung untuk memperoleh informasi yangjelas (B4), petugas memberikan pelayanan yang sopan (D1), petugas memberikan informasi kepada pengunjung dengan bahasa yang mudah dimengerti (E5).

Sepuluh variabel pada kuadran III yang memuat tingkat kepentingan rendah dan kinerjanya juga rendah yaitu pengunjung dapat menjangkau lokasi atau tempat dengan mudah (A1), kantor pos memiliki ruang tunggu yang menarik (A2), 
kantor pos memiliki petugas pelayanan yang berpenampilan rapi (A4), kantor pos memiliki area parkir yang luas (A7), petugas sigap dalam membantu pengunjung (C1), petugas cepat tanggap dalam menghadapi keluhan pengunjung (C2), petugas menindaklanjuti saran dan kritikan dari pengunjung (C4), petugas mempunyai pengetahuan yang memadai di bidangnya (D3), petugas memberikan perhatian kepada pengunjung (E1), petugas peduli kepada pengunjung (E2).

Tiga variabel pada kuadran IV yang memuat petugas terampil dan cekatan dalam melaksanakan tugas (D2), petugas memungut biaya sesuai dengan ketentuan yang berlaku (D4), kantor pos memiliki keamanan area parkir yang baik (D5).

Selanjutnya, dalam analisis kesenjangan ( gap) diperoleh hasil perhitungan pada Tabel 1.

Tabel 1. Hasil Perhitungan Gap

\begin{tabular}{|c|c|c|c|}
\hline Variabel & Kinerja (X) & Kepentingan (Y) & Gap \\
\hline A1 & 3,877 & 4,448 & $-0,571$ \\
\hline A2 & 3,757 & 4,448 & $-0,691$ \\
\hline A3 & 3,940 & 4,586 & $-0,646$ \\
\hline A4 & 3,866 & 4,492 & $-0,626$ \\
\hline A5 & 4,321 & 4,563 & $-1,112$ \\
\hline A6 & 3,892 & 4,507 & $-0,186$ \\
\hline A7 & 4,336 & 4,425 & $-0,533$ \\
\hline B1 & 3,910 & 4,567 & $-0,231$ \\
\hline B2 & 3,933 & 4,604 & $-0,694$ \\
\hline B3 & 4,026 & 4,608 & $-0,675$ \\
\hline B4 & 3,828 & 4,519 & $-0,493$ \\
\hline D1 & 3,840 & 4,422 & $-0,594$ \\
\hline D2 & 3,963 & 4,478 & $-0,638$ \\
\hline D3 & 3,832 & 4,519 & $-0,556$ \\
\hline D4 & 4,340 & 4,451 & $-0,619$ \\
\hline C1 & 4,287 & 4,522 & $-0,182$ \\
\hline C2 & 3,951 & 4,437 & $-0,150$ \\
\hline C3 & 4,299 & 4,474 & $-0,523$ \\
\hline C4 & 3,985 & 4,425 & $-0,126$ \\
\hline D1 & 3,840 & 4,463 & $-0,478$ \\
\hline D2 & 3,787 & 4,351 & $-0,511$ \\
\hline D3 & 3,873 & 4,433 & $-0,646$ \\
\hline D4 & 3,933 & 4,519 & $-0,646$ \\
\hline D5 & 3,892 & 4,519 & $-0,586$ \\
\hline E1 & 4,336 & 4,567 & $-0,533$ \\
\hline E2 & 3,910 & 4,604 & $-0,231$ \\
\hline E3 & 3,933 & 4,608 & $-0,694$ \\
\hline E4 & 4,026 & 4,519 & $-0,675$ \\
\hline E5 & 4,362 & 4,537 & $-0,175$ \\
\hline & & & \\
\hline
\end{tabular}

Dari Tabel 1 terlihat bahwa selisih antara kinerja kantor pos dengan tingkat kepentingan pengunjungan semuanya bernilai negatif. Ini berarti kinerja kantor pos yang diwakili 25 variabel semuanya masih berada di bawah tingkat kepentingan.

\subsection{Uji Normal Multivariat}

Pada Gambar 2 ditampilkan plot Chi-Square data rata-rata per dimensi kinerja dan kepentingan. Dari Gambar 2 dapat dilihat bahwa titik-titik pada plot hampir mendekati garis lurus, hal ini dapat dikatakan data kinerja dan kepentingan dapat memenuhi asumsi normal multivariat. 


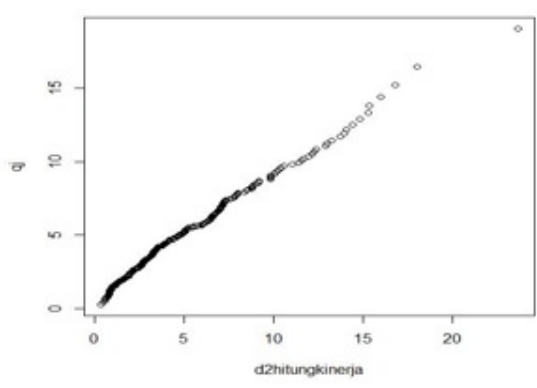

(a)

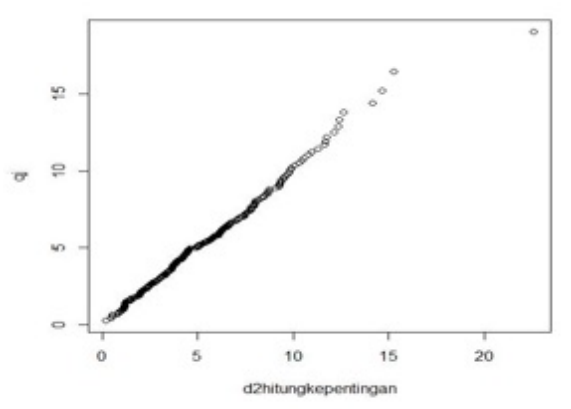

(b)

Gambar 2. Plot Chi-Square (a) Data Rata-rata per Dimensi kinerja (b) Data rata-rata per Dimensi kepentingan

\subsection{Bagan Kendali $T^{2}$ Hotelling}

Gambar 3 dan Gambar 4 menampilkan output bagan kendali data rata-rata per dimensi kinerja dan kepentingan.

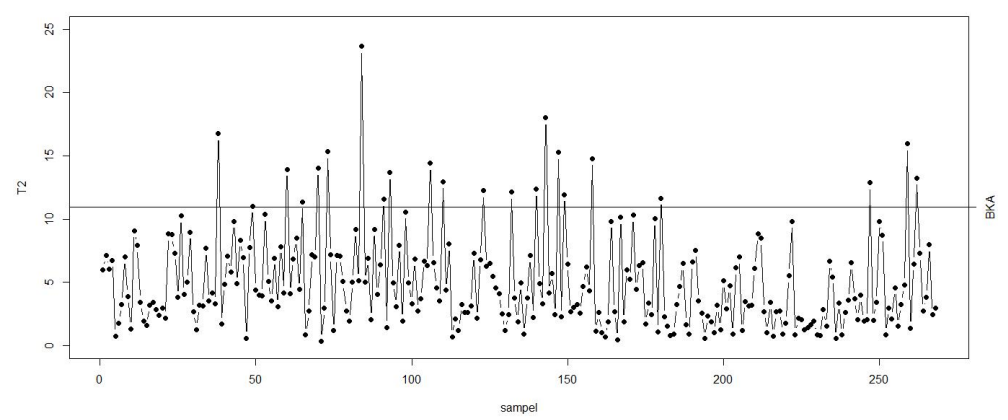

Gambar 3. Bagan Kendali Data rata-rata per Dimensi Kinerja

Dari Gambar 3 terlihat bahwa terdapat 22 titik yang tidak terkendali, sehingga dapat dikatakan bahwa proses belum terkendali secara statistik. Menurut teorinya, untuk pengamatan yang tidak terkendali tersebut harus dilakukan tindakan penyelidikan atau mengidentifikasi penyebabnya. Namun pada kasus ini belum dapat dipastikan penyebab dari pengamatan yang tidak terkendali tersebut. Akan tetapi, jika dikaji lebih dalam lagi dapat dilihat dari karakteristik responden dan diperoleh variabel yang paling berpengaruh adalah variabel $x_{3}$ (dimensi responvesiness) terhadap karakteristik responden berdasarkan alasan menggunakan kantor pos.

Sedangkan, pada Gambar 4 terlihat bahwa terdapat 13 titik yang tidak terkendali, sehingga juga dapat dikatakan bahwa proses belum terkendali secara statistik. Dengan langkah yang sama, pada kasus ini diperoleh tidak ada variabel yang 


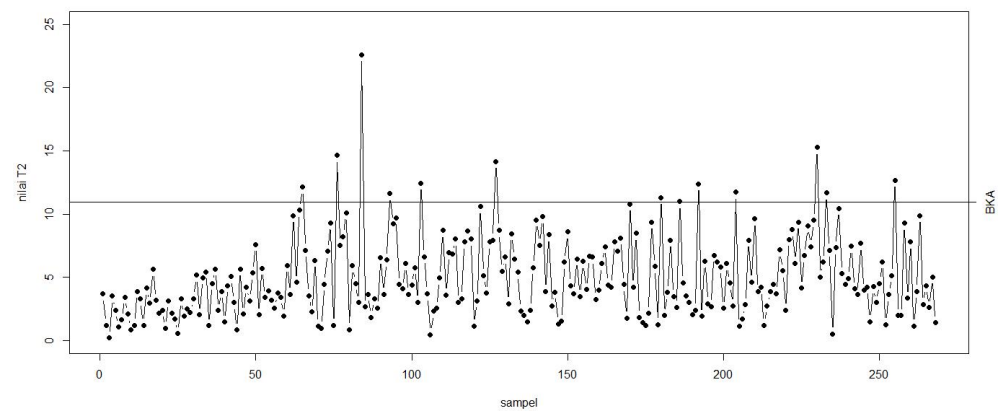

Gambar 4. Bagan Kendali Data rata-rata per Dimensi Kepentingan

berpengaruh terhadap karakteristik responden.

\section{Kesimpulan}

Pada data rata-rata karakteristik dimensi kinerja terdapat 22 pengamatan yang berada di atas Batas Kendali Atas (BKA). Pada data rata-rata karakteristik dimensi kepentingan, sama dengan sebelumnya terdapat 13 pengamatan yang berada di atas Batas Kendali Atas (BKA), sehingga dapat dikatakan bahwa proses kedua data belum terkendali secara statistik. Dalam hal ini belum dapat dipastikan penyebab pengamatan yang tidak terkendali tersebut.

\section{Daftar Pustaka}

[1] Johnson, R. A. dan Wichern, D. W. 1988. Applied Multivariate Statistical Analysis, Second Edition. Prentice-Hall Internasional, New Jersey.

[2] Montgomerry, D. C. 2009. Introduction to Statistical Quality Control, Sixth Edition. John Wiley and Son, Inc : New York.

[3] Tjiptono, F. 2008. Strategi Pemasaran, Edisi ketiga. Andi Offset, Yogyakarta. 